\title{
Dilemma and Path Selection of College and University's Creative and Entrepreneurship Education Reform
}

\author{
Wei Gao ${ }^{1, a}$, Haiying Zhang ${ }^{1, b^{*}}$ and Wei Huang ${ }^{1, c}$ \\ ${ }^{1}$ Qingdao Binhai University, Qingdao, China, 266555

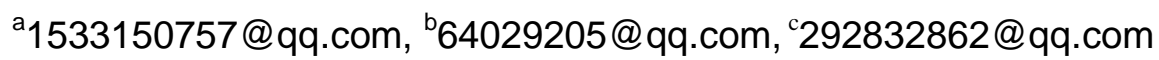

\begin{abstract}
Keywords: Colleges and universities; Creative and entrepreneurship education; Path selection; Path for the creative and entrepreneurship education dilemma in Colleges and Universities
\end{abstract}

\begin{abstract}
China's colleges and universities are gradually implementing reform rather than simple development. Even though the education foundation (hard environment) of college and university education has been built, the educational system (soft environment) with special Chinese characteristics has not been adapted to the industrial structure adjustment and economic development quickly. With the emergence and development of creative and entrepreneurship education, a glittering array of colleges and universities begin to explore their own mode and path to carry out creative and entrepreneurship education activities based on their foundation, actual condition and talent cultivation schemes. Creative and entrepreneurship education is now an important approach for colleges and universities to cultivate talents even though there are various difficulties, which need to be solved. Creative and entrepreneurship education is suggested in National Outline for Medium- and Long-Term Educational Reform and Development as well as the requirement of cultivating high-end talents. In the premise of understanding relative concepts of creative and entrepreneurship education as well as its incubating carrier, we should pay attention to its theoretical predicament, policy dilemma and realistic predicament to come up with the idea that it should take both content-based and extensive paths. What's more, the country should carry pout different ways to support its development from multiple perspectives, which has already become a direction of college and university reform and development. At present, it is in its infancy with lots of problems as well as bottlenecks in terms of educational idea, mode and path. Therefore, we should suggest advanced and perfect education mode and path so as to improve the effectiveness based on common modes. How to build a creative and entrepreneurship education in college and universities has become an important and significant topic.
\end{abstract}

\section{Introduction}

Colleges and universities are deemed as the hubs of talent resources. However, they lack innovational and enterprising talents for a long term, and are seeking for new path and approaches in order to cultivate more talents with the ability to innovate and serve the economic development of the society. Concerning the creative and entrepreneurship education, creation is the base and essential characteristics of entrepreneurship while entrepreneurship is an important carrier and representation. It is actually an educational activity with totally new ideas and talents cultivation mode, which aims to cultivate innovation and entrepreneurship consciousness, spirit and quality of students. Creation or innovation has gradually become the trend of the whole world, which is also the common understanding for countries to facilitate development with various strategies. Creative and entrepreneurship education in China has gone through more than 10 years development, which still cannot meet the requirement for cultivating innovative talents, economic adjustments as well as the continuous development of the society. To tell the truth, it is a very important development tendency. Therefore, colleges and universities should strengthen top-level design to scientifically construct effective mode, select proper improvement path, combine talents cultivation rules. Based on the above, they should also change their ideas, innovate the concepts, clear the direction and position to systematically construct an implementation system with clear targets and from various perspectives to finally explore a new approach for creative and entrepreneurship education. 


\section{Defining the Concept of Creative and Entrepreneurship Education in Colleges and Universities}

Creative and entrepreneurship education should be built based on creation and entrepreneurship and at the same time conform to the design of education system, taking cultivating students' innovative concepts and entrepreneurship ability as the goal. On the one hand, it should help students to master professional knowledge and develop their innovative ability based on educational theory and approaches; on the other hand, it will provide opportunities based on various education resources, disciplinary crossing and integration as well as various social platforms for students so as to encourage them to be build creative and entrepreneurship spirit and become entrepreneurs in reality. Entrepreneurship is a kind of exploratory behavior which can demonstrate the power of human beings and realize their subjectivity and can be deemed as the process from realm of necessity to the realm of freedom. Entrepreneurship education, as the education activity to cultivate entrepreneurs, focuses on the nature of human beings and shape of subjectivity. To take free and comprehensive development of human beings as the core value should be the argumentation of entrepreneurship education. By the way, innovative education is closely to entrepreneurship. As a whole, colleges and universities should advocate creative and entrepreneurship rather than entrepreneurship. As we all know, the entrepreneurship group in China did not receive good education and had low academic qualifications, and there is not enough knowledge-based enterprise talent. In the investigation, there is a question like did you ever start entrepreneurship and $79.06 \%$ students say that they never did because they are not familiar with it. While coupling creative education and entrepreneurship education, value should be prior to behavior in terms of structure sequence so as to firstly cultivate students' creative as well as entrepreneurship consciousness; concerning content integration, schools should introduce the idea of entrepreneurship and at the same time help them to cultivate practical ability and fully play their abilities.

\section{Present Implementation Situation of Creative and Entrepreneurship Education}

Creative and entrepreneurship education is not only considered as an important initiative to drive the employment based on entrepreneurship but also comprehensive combination between creative and entrepreneurship education and professional education. In addition, we should take creative and entrepreneurship as the education philosophy to cultivate innovative students and take it into various sections of higher education system so as to highlight the innovative spirit and consciousness and full play its function to promote the reform and development.

Generally, the creative and entrepreneurship education has received good results based on years' exploration and practice. However, there are still lots of problems remaining to be solved, showing in the following:

Related Theories of Entrepreneurial Universities Remain to be Perfected. Colleges are always considered as the important place to spread knowledge, and research was deemed as the first academic revolution at the end of 1990s. Afterwards, a series of research universities gradually developed which deepened the connotative development. Along with the change of top-level design, many universities in Singapore started to reconstruct and huge changes emerged around 2000. China, granted with more missions in the new era has a different kind of economic environment and the strategy of innovation driving strategy has become the most important one. Based on this, Chinese colleges should also make a difference while the development of entrepreneurship universities is an important development direction. Along with the development of information and knowledge-based economy, entrepreneurship has become another important focus if colleges. However, driving the development based on innovation is not the invention of China. College creative and entrepreneurship education needs the support of theory and the lack of theory will lead to misunderstanding. However, there are not enough relevant theories while most of colleges pay attention to the construction of research colleges, so there is not a clear understanding on both the hardware and software environment for entrepreneurship. At present, the creative and entrepreneurship education is not a project for pure benefits but also to cultivate students' creative 
and creation ability, meanwhile, help them to cooperate and make plans for the long-term development of economy.

Education Concept Can't Keep Pace with the Times. With the continuous reform and advancement of talents cultivation mode and education reform, the situation that colleges pay attention to theoretical knowledge, ignore practice has been changed. Nowadays, education and teaching is still emphasizing the professional, systematic and all-round level of theoretical knowledge while most of colleges run based on the traditional mode with practical training as the focus and are not able to implement the philosophy of experiential training. In addition, most of the schools are too eager to carry out creative and entrepreneurship and only pay attention to few people. They expect to cultivate parts of them to do the entrepreneurship as Great Leap Forward while other people act as the outsiders.

Education and Teaching Content and Form Innovation are not Enough. Judging from the content of creative and entrepreneurship, it highlights policy pronouncements and industry sharing which are narrow and simplified. In addition, there is not enough entrepreneurship cultivation class and practical training. Therefore, students cannot get benefits from this and cannot be able to develop the career. What's more, the implementation of traditional education teaching lacks interactive training and cannot cultivate students' ability to think. Currently, colleges mainly adopt class case and group discussion without innovative and practical training, which will definitely lead to bad education effect.

Talent Training Mode Reform is not Complete. College student creative and entrepreneurship is a complicated and systematic work. However, most colleges haven't integrated this into the talents cultivation mode and education system, so there are no unified talents training scheme can be implemented well. For example, many colleges provide College students employment and career development class as required or selected one, yet they are demonstrated based on lectures and guidance lectures. Only few classes integrate creative and entrepreneurship education into the talent cultivation system to create an independent and formal class let alone multi-level and three-dimensional system. As a result, it is just considered as a function to guide the employment service while integrated resource construction and implementation system is in deficiency without a good result. That is to say, the creative and entrepreneurship education has not been introduced to the implementation sector of talents cultivation system and has not been infiltrated into the process of cultivating talents.

\section{Constructing the Path to Realize the Innovation and Entrepreneurship Education.}

Constructing the Curriculum System of Innovation and Entrepreneurship Education. The entrepreneurship education class should be implemented based on module, credits, practice and area. Module means the entrepreneurship consciousness, quality, management knowledge; entrepreneurship area and training should be modularized. Credit means to develop creative and entrepreneurship class, provide selective classes, combine relevant excellent courses to on the one hand provide chances for them to get trained and on the other hand control the quality. Practice means that college students should participate in competition contest, training and business incubator training. What's more, practice also means that there should be entrepreneurship forum to provide face to face communication between entrepreneurs and colleges. Area means entrepreneurship class should be adapted to the economy development of local areas with both general courses and special courses. In addition, general course should refer to relevant experience of foreign countries while special courses should be designed based on the local economic development structure and running features of various countries.

Creative and Entrepreneurship Faculties. The key of creative and entrepreneurship is the construction of faculties. Open to the public, build a professional and stable team, including college teachers, government offices for the economic development, successful entrepreneurs and investors to participate in the touring team is very urgent. At the same time, we should vigorously carry out practical training to change the condition that there is not enough teachers and good quality. In addition, teachers should be able to work in enterprises so as to raise their social status. We should 
also encourage teachers to carry out practice in enterprises while colleges should build relative school run enterprises. Moreover, case demonstration teaching and symposium should be added to exchange ideas and improve the education quality.

Creative and Entrepreneurship Practice Base. Entrepreneurship is a practical career and a whole entrepreneurship education system should include practice. Colleges with good resources can build entrepreneurship base so as to provide policy and preference in terms of capital, place, equipment and facility. At the same time, college students should be exposed to various educations and practical training related to creative and entrepreneurship education. Meanwhile, colleges and students should work together. For colleges, they should strengthen the teaching reform and provide entrepreneurship class with flexible credit calculating methods so as to provide students with place, environment, policy, and capital etc.; students should take the initiative to carry out various creative and entrepreneurship activities such as building a company or ignite a new idea etc. In addition, the creative and entrepreneurship practice can also include finance operation, business service, achievement transformation and other simulating experiments.

Set Up a Creative and Entrepreneurship Association for College Students. Creative and entrepreneurship association for college students is a basic organization for creative and entrepreneurship education, which can be also deemed as a platform for students to directly participate in activities and communicate. From the perspective of quality education, college should cultivate students from multiple perspectives and try to strengthen students' ideas to carry out entrepreneurship. Moreover, students from different places can fully communicate and have mutual improvement through the organization, which can act as a bridge linking the college and the public.

\section{References}

[1] Li Jingxin. How can library lectures play a role in college entrepreneurship [J]. Library Journal

[2] Han Wenshen. Entrepreneurship in campus culture constructing CJ7 Journal of Ningbo University (Education science)

[3] Xi Yang, Xiang Rong. Educational Philosophy of entrepreneurship education's talents cultivation mode[J7.China Metallurgical Education

[4] Yang Yongchao. Enlightenment of enterprise creation and entrepreneurship to college creative and entrepreneurship education [J7 Journal of Harbin Institute of Vocational Technology

[5] Wu Jinqiu. The positioning of college creative and entrepreneurship education philosophy $\lceil\mathrm{N} 1$. China Education Daily

[6] Gao Xiaojie, Cao Shengli. Creative and entrepreneurship- Cultivating pioneers for the new era/Organize Annual Educational Seminar for higher education China Higher Education Research. Term 7 of 2007

[7] Li Qunru. Exploration and practice of college students creative and entrepreneurship education, Human resource management. Term 62011

Zhou Qiujiang. Study on the current condition and realization path of college students' entrepreneurship education. Journal of Ningbo University, Term 4, 2007

[8] Li Jiahua, $\mathrm{Hu} \mathrm{Ou}$. The positioning, barriers and path for young creative talents cultivation Youth Studies. Term 1,2011

[9] Sang Dawei, Zhu Jian. Take entrepreneurship colleges as the carrier to push Pioneering Education Of Higher Learning Institutions Employment Guidance, term 62011 